\title{
Tenda do abraço: Uma metodologia de cuidado guiada pelo afeto
}

\author{
Hug tent: A caring methodology guided by affection \\ Carpa aprazo: Una metodología solidaria guiada por el afecto
}

Recebido: 18/01/2021 | Revisado: 21/01/2021 | Aceito: 26/01/2021 | Publicado: 03/02/2021

\author{
Jackeline de Freitas Costa \\ ORCID: https://orcid.org/0000-0001-5693-7917 \\ Universidade Estadual do Rio Grande do Norte, Brasil \\ E-mail: jackfc2@hotmail.com \\ Isabel Cristina Amaral de Sousa Rosso Nelson \\ ORCID: https://orcid.org/0000-0003-4840-6950 \\ Universidade Estadual do Rio Grande do Norte, Brasil \\ E-mail: isabelrosso@uern.br \\ Gleiber Couto \\ ORCID: https://orcid.org/0000-0002-1139-811X \\ Universidade Federal de Catalão, Brasil \\ E-mail: gleibercouto@yahoo.com.br \\ Raiane Caroline da Silva França \\ ORCID: https://orcid.org/0000-0003-1346-1554 \\ Universidade Estadual do Rio Grande do Norte, Brasil \\ E-mail: raianecsf@gmail.com
}

\begin{abstract}
Resumo
O presente trabalho tem como principal objetivo apresentar a Tenda do Abraço como uma metodologia de cuidado sistematizada no âmbito das Práticas Integrativas e Complementares em Saúde, dentro uma abordagem das Vivências Lúdicas Integrativas. É uma pesquisa de método qualitativo, foi realizada uma pesquisa-ação existencial. O públicoalvo foram 48 estudantes da Faculdade de Enfermagem - FAEN da Universidade Estadual do Rio Grande do Norte UERN. A tenda do abraço é uma metodologia itinerante de cuidado que evidencia a necessidade de cultivar novos olhares para si e para o outro, oportunizando momentos de cuidado, escuta, fala e toques. Por meio de um roteiro não engessado em que os sujeitos têm a possibilidade de cuidar de si e perceber a necessidade do cuidado com o outro, com o aparato das PICS. A Tenda do Abraço perpassa quatro etapas principais: acolhimento afetivo; tecendo saberes; conexões e reflexões; cooperação e autocuidado. A Tenda do Abraço apresentou-se como uma metodologia de cuidado humanescente, sistematizada e potente para conexão consigo e com o outro, melhorando a qualidade das interações interpessoais dos universitários.
\end{abstract}

Palavras-chave: Terapias complementares; Estudantes de enfermagem; Vivências lúdicas.

\begin{abstract}
The present work has as main objective to present the Tent of Hug as a systematized care methodology within the scope of Integrative and Complementary Practices in Health, within an approach of Integrative Playful Experiences. It is a qualitative method research, an existential action research was carried out. The target audience was 48 students from the Faculty of Nursing - FAEN of the State University of Rio Grande do Norte - UERN. The hug tent is an itinerant care methodology that highlights the need to cultivate new perspectives for oneself and for the other, providing opportunities for care, listening, speaking and touching. Through a non-cast script in which the subjects have the possibility to take care of themselves and realize the need to care for others, with the PICS apparatus. The Tent of Embrace goes through four main stages: affective reception; weaving knowledge; connections and reflections; cooperation and self-care. Tenda do Abraço was presented as a humanescent, systematic and powerful care methodology for connection with oneself and with the other, improving the quality of interpersonal interactions among university students.
\end{abstract}

Keywords: Complementary therapies; Nursing students; Playful experiences.

\section{Resumen}

El presente trabajo tiene como objetivo principal presentar la Carpa del Abrazo como una metodología asistencial sistematizada en el ámbito de las Prácticas Integrativas y Complementarias en Salud, dentro de un enfoque de Experiencias Lúdicas Integradoras. Es una investigación de método cualitativo, se realizó una investigación de acción existencial. El público objetivo fueron 48 estudiantes de la Facultad de Enfermería - FAEN de la Universidad Estatal de Rio Grande do Norte - UERN. La carpa del abrazo es una metodología de cuidado itinerante que resalta la necesidad de cultivar nuevas perspectivas para uno mismo y para el otro, brindando oportunidades para cuidar, escuchar, hablar y tocar. A través de un guión sin elenco en el que los sujetos tienen la posibilidad de cuidarse a sí mismos y darse cuenta de la necesidad de cuidar a los demás, con el aparato PICS. La Tienda del Abrazo pasa por cuatro etapas principales: recepción afectiva; tejido de conocimiento; conexiones y reflexiones; cooperación y 
autocuidado. Tenda do Abraço se presentó como una metodología de atención humana, sistemática y potente para la conexión con uno mismo y con el otro, mejorando la calidad de las interacciones interpersonales entre los estudiantes universitarios.

Palabras clave: Terapias complementarias; Estudiantes de enfermería; Experiencias lúdicas.

\section{Introdução}

As Práticas integrativas e complementares - PICS constituem-se como um fenômeno contemporâneo social e institucional no campo da saúde, sendo um movimento que busca romper a interface saúde-doença (Tesser \& Sousa, 2012), favorecendo produção de afetos e afecções (Rolnik, 2006).

Nesse campo de atuação surge e se sustenta com o olhar de um processo de saúde e doença amplos, com anseio de um cuidado integral do ser humano, com cuidados terapêuticos eficazes e seguros, com processos naturais de promoção de saúde, prevenção e recuperação de doença (Tesser, Sousa \& Nascimento, 2018, OMS, 2013, Brasil, 2006). As PICS não só complementam o cuidado tradicional como elas contribuem para uma ampliação e aprofundamento do olhar do cuidado e oferecimento de outras terapias, em todos os níveis de atenção, pincipalmente na atenção básica, ou seja, elas também integram o cuidado.

No Brasil, apenas em 2006, foi regulamentada, a Política Nacional de Práticas Integrativas e Complementares do Sistema Único de Saúde - PNPIC-SUS, tendo como pilar a Medicina Tradicional Chinesa - MTC e pensando uma atenção ao cuidado mais humanizado e integral (Brasil, 2006). A Política Estadual de Práticas Integrativas e Complementares do Rio Grande do Norte trouxe duas novas abordagens metodológicas, sendo elas: Práticas Corporais Transdisciplinares e Vivências Lúdicas Integrativas. As Vivências Lúdicas Integrativas "propiciam diferentes modos de sentir o fluir das emoções de alegria em contextos socioculturais específicos do adoecimento humano, buscando corporalizar o princípio de integralidade da vida" (Rio Grande do Norte, 2011), pilares estes que a Tenda do Abraço surge, se ancora e estabelece, com o olhar e cuidado afetivo, humanescente (Cavalcanti, 2006, Sampaio, 2010) e na abordagem da salutogênese (0liveira \& costa, 2012, Luisa \& Elisa, 2014, Marçal, et al, 2018).

Foi com o intuito de levar até as pessoas (comunidades, escolas, local de trabalho, universidades...) mais diálogo, amor, afeto e partilha de conhecimento que a Tenda do Abraço foi idealizada. Os efeitos dos encontros promovidos pela Tenda do Abraço são para além das afetações das pessoas que participam, pois, ao mesmo tempo em que o indivíduo é afetado, ele também promove afetações em outros corpos (Mansano \& Carvalho, 2016).

É um se permitir aos bons encontros, expandindo as afetações e se abrindo para conhecer outros modos de vida e sentir o que melhor se relaciona com os nossos corpos (Espinosa, 2007), promovendo novas vivências e conhecimentos, com amorosidade, respeito por cada história, muito diálogo e olho-no-olho. Sendo assim, o presente trabalho tem como principal objetivo apresentar a Tenda do Abraço como uma metodologia de cuidado sistematizada no âmbito das Práticas Integrativas e Complementares em Saúde, dentro uma abordagem das Vivências Lúdicas Integrativas.

\section{Metodologia}

Esta pesquisa é de natureza qualitativa, com a abordagem da pesquisa-ação existencial, a qual observou como os acadêmicos de enfermagem da UERN, percebiam cada etapa da tenda do Abraço (Barbie, 2007). O método é o caminho traçado para com a finalidade de descobrir algo, com ele é possível identificar como fazer o processo acontecer, onde está e onde se quer chegar, e no método qualitativo o olhar do pesquisador tem grande relevância (Pereira, et al, 2018).

Na pesquisa-ação existencial traz em si duas propostas primordiais: a transformação da realidade pesquisada e o cultivo do conhecimento. A pesquisa-ação busca compreender e explicar a realidade estudado com intuito de transforção dos modos de existir, devendo permitir que os envolvidos expressem suas necessecidade individuais e coletivas (Barbier, 2002). 
O pesquisador precisa ser muito além de um especialista, ele necessita se abrir para um encontro humano. A pesquisaação requer um pesquisador com evolvimento afetivo com os envolvidos, sem fazer parte do mesmo grupo, exigindo uma postura autonoma. Deve-se implicar com o contexto social o qual está inserido e nos jogos de desejos e interesses do invividuos que compõe o grupo (Barbier, 2002; Barbier, 2007).

\section{Cenário da pesquisa}

A pesquisa foi realizada na Universidade Estadual do Rio Grande do Norte no campus de enfermagem da cidade de Mossoró - RN, Faculdade de Enfermagem - FAEN. No momento em que a pesquisa deu início contava com 92 alunos, sendo esses divididos entre as turmas do $1^{\circ}, 3^{\circ}, 5^{\circ}, 7^{\circ}$ e $9^{\circ}$ período.

\section{População da pesquisa}

Participaram um total de 48 alunos, sendo esses do $1^{\circ}, 3^{\circ}$ e $5^{\circ}$ período do curso de enfermagem da Faculdade de Enfermagem - FAEN da Universidade Estadual do Rio Grande do Norte.

\section{Coleta de dados}

A coleta de dados aconteceu entre os dias 30 de julho a 05 de dezembro de 2019. Do dia 30 de julho a 03 de setembro foram realizados a explicação sobre o processo da pesquisa, assinatura do Termo de Consentimento Livre e Esclarecido TCLE. Do dia 09 de setembro ao dia 08 de novembro ocorreram as tendas do abraço. E de 12 de novembro a 05 de dezembro os participantes responderam o formulário. Todo o processo de coleta de dados foi realizado de forma coletiva, em sala de aula, cada turma em sua sala.

Toda pesquisa foi vinculada ao Núcleo de Práticas integrativas e complementares - NUPICS da Universidade Estadual do Rio Grande do Norte. O NUPICS busca aproximar a universidade aos diversos outros setores da sociedade, possibilitando e incentivando práticas de autocuidado por meio das PICS (Nelson, et al, 2020). No primeiro contato com os alunos foi apresentada a proposta e o convite para participação voluntária da pesquisa. No mesmo momento, os alunos que tiveram interesse em participar assinaram o TCLE.

Ao longo de toda a pesquisa foi utilizada a observação participante existencial, a escuta sensível o diário vivencial, como ferramenta da pesquisa-ação existencial para ampliação do cuidado e descobertas sobre a potência do encontro daqueles alunos com a Tenda do Abraço. A observação participante existencial foi essencial na percepção de como o grupo estava aceitando cada momento e permitindo-se vivenciar e deixar fluir. A escuta sensível se constitui em olhar empático, na busca de compreender ideias, histórias, valores que cada um apresentava. E, o diário vivencial, permitiu a pesquisadora registrar suas percepções e afetações dos momentos vividos em cada encontro (Sampaio, 2009).

Com intervalos consecutivos de quinze dias foram realizadas as Tendas do Abraço, com duração média de 1 hora. A primeira tenda teve como tema Eu comigo; a segunda, Eu e o outro; e a terceira teve como tema Eu e o meio que vivo. No decorrer de cada tenda foi feito os arquivos existenciais, com intuito de registrar e perceber cada afetação nos envolvidos. A tenda do abraço é uma metodologia de cuidado guiado pelo afeto e estruturara em quatro momentos principais:

- Acolhimento afetivo: O formato da tenda é idealizado para que todos, ao chegarem já se sintam acolhidos: um cheirinho agradável da aromaterapia, filtros de sonhos espalhados pelo ambiente, um chazinho para quem gostar. Todos que chegam são acolhidos com sorrisos e muito afeto. É o espaço também da sensibilização conduzida por musicas, fabulas, meditações... Tudo conforme o tema proposto para a tenda. 
- Tecendo saberes: A partir da sensibilização, os participantes são convidados, por meio de perguntas deparadoras, a refletirem sobre os seus conhecimentos prévios sobre a temática em questão. Sempre exercitando pensar que cada um trás a relevância do seu próprio saber, todos são protagonistas naquele momento.

- Conexões e reflexões: o momento que liga o conhecimento adquirido com as histórias de vidas. Ao compartilhar o vivido, todos os outros participantes vão se identificando com alguma ocasião de suas próprias vidas, aflorando a escuta, afetividade e conexão.

- Cooperação e autocuidado: É o fechamento, onde todos são convidados a ficarem de pé, dá um passo a frente e forma um grande abraço coletivo, dentro do abraço existe o ritual de sentir o próprio corpo, sentir a presença do outro e perceber a importância do outro em suas vidas e a importância de cada um na vida do outro.

No que se refere aos aspectos éticos, à pesquisa foi vinculada ao parecer aprovado do Comitê de Ética na Pesquisa no ambulatório integrativo: promovendo saúde por meio das práticas integrativas e complementares em saúde, CAAE: 03438418.2.0000.5294, conforme as determinações da Resolução n 466/12 do Conselho Nacional de Saúde (CNS). Os dados colhidos estão guardados pela pesquisadora responsável da pesquisa e serão conservados em segurança e sigilo na sua residência pelo período de 5 anos.

\section{Analise dos dados}

Os dados foram submetidos a análise de conteúdo propostos por Bardin (2009), adotando a seguinte ordem: leitura flutuante, organização e preparação do material, uma pré-análise; exploração do material e identificação das categorias temáticas; e o agrupamento dos dados por categorias e a interpretação a luz do referencial teórico. Sendo verificados como categoria os quatros momentos da Tenda do Abraço.

Tendo em vista a confidencialidade dos dados e bem como identidade dos participantes da pesquisa, de forma humanescente as identidades formam substituídas por nomes populares de abraços, identificados pela pesquisadora no decorrer da pesquisa. A exemplo: abraço de Urso foi nomeado o participante que mais demostrou entusiasma no momento do abraço; Abraço de amizade foi para aquele que demostrava passar com seu abraço muito cuidado; Abraço mais ou menos que não mostrou tanta vontade em retribuir o abraço; e assim por diante. O abraço é antes de qualquer coisa um ato de cuidado, proteção e acolhimento, e são esses atributos que buscamos trilar com a Tenda do Abraço.

\section{Resultados e Discussão}

\section{Caminho metodológico da tenda do abraço}

A tenda do abraço é uma metodologia itinerante de cuidado que evidencia a necessidade de cultivar novos olhares para si e para o outro, oportunizando momentos de cuidado, escuta, fala e toques. Por meio de um roteiro não engessado em que os sujeitos têm a possibilidade de cuidar de si e perceber a necessidade do cuidado com o outro, com o aparato das PICS.

É um se permitir saber conversar com amorosidade, é utilizar o mesmo espaço com um novo olhar, um novo jeito de se relacionar, usufruindo da liberdade de ser quem cada um é. Para Mariotti (2000), saber conversar significa saber perguntar, com intuito de promover alterações no outro, enriquecendo as experiências do momento presente em um processo diálogo, onde cada indivíduo tem a possibilidade de reorganizar suas emoções e um novo contato com as suas relações afetivas, oportunizando-se um viver mais harmônico, se permitindo seguir o fluxo da vida, procurando viver de forma mais saudável, fortalecendo e encontrando novas redes de afetos. 
A tenda do abraço tem uma ambiência acolhedora e afetiva, com o aporte na Política Nacional de Humanização PNH defende a valorização da ambiência como uma ferramenta que colabora com melhores relações, tendo em vista a busca por organização de espaços saudáveis e acolhedores. Nesse contexto, assim como PNH, a Tenda do Abraço também apresenta como base o conceito de transversalidade por meio da experiência de cada participante interagindo com a integração e conexão de diferentes práticas e saberes (Brasil, 2013).

Mesmo a Tenda do Abraço tendo temáticas previamente escolhida e elaborada, ela não tem nenhum tipo de intenção em focar e tratar processos de adoecimentos, mas sim, de despertar nos sujeitos uma nova forma de olhar para vida, de olhar para cuidado de si e do outro como algo circular, assim como próprio formato físico da tenda (em roda), buscando uma relação com o todo (consigo, com o outro e com o meio).

A Tenda do Abraço é sistematizada em quatro momentos mais pontuais e construtores os quais se inter-relacionam com os quatro pilares da humanescência (Sampaio, 2009).

\section{Primeiro momento - acolhimento afetivo}

O acolhimento é a ação de se aproximar, inclusão, é um estar com e um estar perto, aceitando, ouvindo, recebendo os que estão chegando ao mesmo tempo aos que já estão ali. Quando se acolhe ao tempo, afirma-se uma relação com alguém. E é assim, com compromisso no reconhecimento do outro, acolhendo suas diferenças, sentimentos, modos de vida e proporcionando encontros potentes que o acolhimento se constitui como a diretriz de maior relevância ética e estética da Política Nacional de Humanização - PNH e do Sistema Único de Saúde - SUS, comprometida com o coletivo, estimulando protagonismo e vida (Brasil, 2010).

"Um encontro para acalmar, retirando o estresse do cotidiano e fazendo com que nós alunos pudéssemos nos aproximar. Foi muito importante a forma na qual fomos acolhidos e em como aquele encontro fazia bem para o resto do dia”. (Abraço cara a cara)

"Foi um momento extremamente proveitoso, que me aproximou da minha essência, me conduziu a um processo de autoconhecimento". (Abraço com beijo)

"Muito bom. Pois me senti bastante acolhida e confortável naquele espaço de reflexão". (Abraço sem querer)

Acolhimento está conectado a ação de cuidado. Cuidar é entrar em sintonia com o outro, com o ambiente, é escuta, comunhão, cordialidade, uma convivência amorosa (Boff, 2005). Gerando com isso a sensibilização entre os envolvidos, sensibilizar é a própria habilidade de sentir e de ser afetado. Tanto a sensibilidade como a afetividade são forças que movimentam, comovem, bagunçam e inquieta os envolvidos (Magalhães, 2011).

Na tenda, esse momento é registrado por cada chegada, troca de olhar cuidadoso, sorrisos, abraços, boas vindas, a breve explicação sobre a vivência da Tenda do Abraço e a sensibilização. A sensibilização é conduzida também por meio de ferramentas (músicas, dinâmicas, fábulas, poesias, contos, meditações...) que transmitam reflexões sobre o momento, conforme tema e contexto a ser discutido. A ludicidade (Sampaio, 2009) é um componente muito presente nessa etapa, apesar de perpassar todas as outras.

\section{Segundo momento - tecendo saberes}

É um momento de troca e construção de saberes, não existe uma postura vertical de um ensina e outros apreendem, há uma articulação e confronto recíproco de saberes, em um formato horizontal, proporcionando um espaço de colaboração, no qual todos os envolvidos são participantes e construtores daquele momento e de novas realidades (Félix-Silva, et al, 2015). 
"Eu comecei a conversar mais com meus colegas sobre outras coisas além da vida acadêmica, e o quanto é importante termos empatia e saber ouvir também. E está deixando a gente mais próximos”. (Abraço grupal)

"Mesmo não tendo total conhecimento sobre todos, pude dá o melhor de mim para ajudar alguém ou até mesmo para confiar para conversar e se sentir acolhido" (Abraço mais ou menos)

Essa construção de saberes, além de harmonizar os conhecimentos expressados pelo o grupo, proporcionando mais integração e, sobretudo, maior possibilidade de transformação da realidade, com direcionamento de onde se pode intervir. Tendo em vista que a aprendizagem é algo construtivo, reconstrutivo, transformador (Freire, 2011). Há nesse momento a reflexões sobre o tema com direcionamento e a sua conexão com o cuidado de si e o cuidado com o outro, com consciência que naquele espaço não tem como o objetivo a transmissão de informação, mas sim, de estimular reflexões.

Não existe um lugar centralizado de fala, todos são protagonistas com sua as emoções, sentimentos, lembranças, conhecimento, fala e escuta. Não existe saber mais relevante do que outro o que permanece é o diálogo sobre diferentes saberes.

\section{Terceiro momento - Conexões e reflexões}

Momento de articulação do conhecimento com as histórias vividas. É a partir do compartilhar experiências de vidas que flui a conexão e afetação para e com o outro, onde cada um pode se oportunizar a olhar para o seu vivido através do vivido do outro e assim perceber formas e possibilidades de mudanças, ressignificação ou até mesmo de alcançando um melhor caminho.

\footnotetext{
"O mais importante foi a possibilidade de reflexão, autoconhecimento, conhecimento do próximo, coisas que muitas vezes não destinamos sequer uma pequena parcela do dia para realizar. A tenda possibilitou a descoberta e ajudou a colocar determinados sentimentos e ações em prática, resultando em dias mais amenos e melhores". (Abraço rosto colado)
}

"As tendas permitiram conhecer e estreitar os laços com colegas e amigos que já conviviam durante dois anos, porém, desconheciam diversos sentimentos e histórias relatadas por eles".

(Abraço relâmpago)

É visível que quando se é construído em conjunto, com o outro e junto ao outro, mais saberes são difundidos, e isso, por si, já torna a Tenda do Abraço transformadora, tendo em vista que após o termino de cada encontro, cada um leva um pouco de cada um, carrega consigo um pouco do que foi vivenciado e com a possibilidade de introduzir em outros contextos da vida, na casa, no trabalho, na universidade... Com novos olhares, com novos fazeres, com novos afetos (Meneses, et al, 2017).

“A liberdade de expressar o que se passa dentro de nós. Olhar o lado do outro e perceber que ele também enfrenta problemas. Me tornei menos egoísta e mais humana”. (Abraço do fundo do coração)

“Percebi que comecei a me preocupar mais com os sentimentos das pessoas". (Abraço de amizade)

“Acho que ajudou a minha observação perante os problemas dos outros, entender que todos tem problemas e sempre podemos ajudar de alguma forma”. (Abraço de amor)

Por meio da reflexão, fala e escuta, as pessoas vão conseguindo se adaptar e ressignificar as situações vivenciadas. Refletindo sobre as experiências, se permitem a demostrar suas competencias com mais autoconfiança, autoestima, clareza e até mesmo aceitando mudanças com mais facilidade. O que se conecta também com a sensibilização (Sampaio, 2009), no fazer refletir por meio da junção do saber com o vivido. 
É a partir dos bons encontros, prevendo a escuta qualificada, onde todos tem o direito de falar e de ser escutado, que vai acontecendo um permiti-se o desenvolvimento de uma relação de amorosidade consigo e com o outro (Leal, 2007, Espinosa, 2015).

Ao tomar consciência da experiência do outro, as conexões são estabelecidas com a sua própria vida, abrindo-se para fazer descobertas, percebendo que cada pessoa tem a sua trajetória e os seus saberes, possibilitando olhares de mais amorosidade.

Os participantes se identificam com as falas e vivências um dos outros, ocorrendo uma identificação e um reconhecimento de si nas histórias do outro, apontando que tal identificação impulsiona a circularidade e singularidade de cada vivência. A escuta dá passagem a novas reflexões e práticas, oferecendo aos envolvidos, oportunidades de estabelecer vínculos entre si e de proporcionar acolhimento mais efetivo um com outro (Gadelha, 2015). Fortalecendo a relação entre os envolvidos e contribuindo para elaboração de nossos sentidos para suas vivências e aprendizagem significativa, o que só é possível com reflexão baseada na generosidade e na afetividade (Klausen, 2017).

\section{Quarto momento - Cooperação e autocuidado}

O abraço cria um círculo de cooperação que promove o crescimento e a cura. Quando abraça o outro num momento de compreensão, é mostrado os sentimentos e reafirmado a crença no que é sentido (Pereira \& Lapa Esteves, 2010).

Mariotti (2000) pontua que saber abraçar pressupõe saber amar e quem ama oferece cuidado, para ver o outro e sentir vontade de abraçar, amar, é necessário primeiro olhar para si mesmo, para a partir de então ir se relacionando com o mundo. Aprender a abraçar é se abrir para si, para o outro, para a vida. Ao abrir os braços para abraçar, também estar permitindo abrir o coração para amar.

"A temática e proposta em si. Deixou a turma mais unida, pois todos vimos que estamos no mesmo "barco" e que unidos conseguiremos passar pelas dificuldades mais rapidamente" (Abraço sem querer)

"Foram momentos de reflexão e autoconhecimento que permitiu analisar sentimentos meio ao espaço ao qual estamos inseridos e que devido as nossas rotinas corriqueiras levamos tudo no automático". (Abraço relâmpago)

O amor liberta e compreende, é a expressão máxima da vida, é com ele que existe o cuidado, a expressão de harmonia e zelo (Moraes, 2003). Afinal, "sem cuidado e sem ternura, a vida não floresce. A chama da vida tende a se extinguir mais rapidamente" (Moraes, 2003, p. 278).

O fechamento da Tenda do Abraço é para além de uma despedida, é um alerta que ninguém está sozinho, tendo em vista que passa a existir uma egrégora de cuidado e afeto. E assim, a ascendência da tenda do abraço se constitui e se fortalece na construção de vínculos, escuta, acolhimento e a afetividade para que aquele espaço seja de fato terapêutico e transformador na vida dos que de alguma forma estão fazendo parte daquele processo. No momento da tenda todos são protagonistas, seja com a sua experiência de vida, com o seu caloroso abraço, com saberes científico ou popular, com olhar cuidadoso. Todos se fazem atores e produtores de novos fazeres.

\section{Considerações Finais}

Pode-se evidenciar que a Tenda do Abraço se apresentou como metodologia de cuidado sistematizada, humanescente, inovadora, potente, que fortalece a conexão consigo e com o outro e promover afetações, é uma possibilidade, não biomédica, de se refazer em meio a si mesmo e ao entorno, com o poder da fala, escuta e toque se produz vida. Sendo assim, possível 
caracterizar a Tenda do Abraço como uma Vivência Lúdica Integrativa no contexto das Práticas Integrativas e Complementares em Saúde.

Espera-se que a tenda do abraço seja uma metodologia de cuidado que venha a contribuir em múltiplas situações, tendo em vista que com ela é possível fazer emergir diferentes contextos da vida, sendo o cuidado de si e o olhar humanescente para outro a sua centralidade. Almeja-se que essa pesquisa venha contribuir para um novo olhar no cuidado de si e do outro no meio acadêmico.

Desde já, sugere-se que ocorram novas pesquisas com a Tenda do Abraço usando outras fontes metodológicas e diversos públicos alvo, contribuindo com suporte para institucionalização enquanto Vivências Lúdicas no âmbito das Práticas Integrativas e Complementares em Saúde. Para além disso, o percurso desse presente estudo possibilitou aos participantes a um momento de cuidado, de ampliar sua visão, reflexão sobre o cuidado de si, com outro e com o seu entorno, gerando mudanças em suas vidas. Em cada encontro, grandes enxurradas de partilha de afetos.

\section{Referências}

Barbier, R. (2007). A pesquisa-ação. Tradução de Lucie Dibio. Liber Libro.

Barbier, R. (2002). A pesquisa-ação. Tradução Lucie Didio. Plano Editora.

Brasil (2006). Política Nacional de Práticas Integrativas e Complementares no SUS. Ministério da Saúde.

Brasil (2013). Política Nacional de Humanização.Ministério da Saúde.

Brasil (2010). Diretrizes do NASF: Núcleo de Apoio a Saúde da Família / Ministério da Saúde, Secretaria de Atenção à Saúde, Departamento de Atenção Básica. Brasília: Ministério da Saúde.

Cavalcanti, K. B. (2006). Para abraçar a humanescência na pedagogia vivencial. Trabalho apresentado no XII Endipe - Encontro Nacional de Didática e Prática de Ensino, Recife.

Espinosa, B. (2007). Ética. Trad. de Tomaz Tadeu. Autêntica.

Espinosa, B. (2015). Ética. Belo Horizonte: Autêntica. Edusp. Tradução grupo de estudo espinosanos.

Félix-Silva, A. V., Nascimento, M. V. N., Albuquerque, M. M. R., Cunha, M. S. G., \& Gadelha, M. J. A. (2015). A tenda do conto como prática integrativa de cuidado na atenção básica. Natal: Edunp.

Freire, P. (2011). Pedagogia do oprimido. Revisada e atualizada. Rio de Janeiro: Paz e Terra.

Leal, O. F., Schuch, P., Jardim, D. F., Cuartas, M. V., Sánchez, T. G., Moraes, A. M., \& Segarra, J. J. (2014). Desdisciplinar a antropologia: diálogo com eduardo restrepo. Horizontes Antropológicos, 20 (41) 359-379.

Gardelha, M. J. A. (2015). Artes de viver: a tenda do conto (recordações, dores e sensibilidade no cuidado em saúde). 2015.198 f. Tese (Doutorado) - Curso de Programa de Pós Graduação em Ciências Sociais, Universidade Federal do Rio Grande do Norte, Natal.

Klausen, L. S. (2017). Aprendizagem significativa: um desafio. EDUCERE: XIII Congresso Nacional de Educação. Formação de professores: contextos, sentidos e práticas.

Luisa, R. C., \& Elisa, M. V. (2014). Estado actual de la salutogénesis en España Quince años de investigación. Enferm. glob., 13 (34).

Mansano, S. R. V., \& Carvalho, P. R. Psicologia, Filosofia e meio ambiente: delineando o conceito de sustentabilidade afetiva. Estudos e Pesquisas em Psicologia, 16 (3), 696-714.

Mariotti, H. (2000). As paixões do Ego: Complexidade, política e solidariedade. Palas Athena.

Marçal, C. C. B., Heidemann, I. T. S. B., Fernandes, G. C. M., Rumor, P. C. F., \& Oliveira, L. S. (2018). A salutogênese na pesquisa em saúde: uma revisão integrativa. Revista Enfermagem UERJ, 26, 1-6.

Meneses, M. N., Ubessi, L. D., Lemões, M. A., Machado, R. A., Friedrich, N. R., Jardim, V. M. R., \& Lange, C. (2015). Tendas do afeto como um 'coração' em pulsação popular na extensão em saúde. Rev. APS, 18 (4), $544-547$.

Morais, M. C. (2003). Educar na biologia do amor e da solidariedade. Petrópolis: Vozes.

Nelson, I. C. A. S. R., Bezerra, K. P., Costa, K. F. L., Oliveira, L. C., Vieira, A. M., Fernandes, A. C. L., Queiro, J. C., \& Lima, M. F. A. P. (2020). Tecnologias de informação e comunicação na atenção à saúde mental de profissionais da saúde no contexto da pandemia da COVID-19. Research, Society and Development, 9 (10), 1-19. 
Research, Society and Development, v. 10, n. 2, e3610212133, 2021

(CC BY 4.0) | ISSN 2525-3409 | DOI: http://dx.doi.org/10.33448/rsd-v10i2.12133

Oliveira, C. C., \& Costa, A. L. (2012). Viver o estado terminal de um familiar: leitura salutogénica de resultados de um estudo de caso. Saúde e Sociedade, 21 (3), 698-709.

OMS - Organização Mundial De Saúde. Estratégia De Medicina Tradicional Da OMS: 2014-2023. 2013

Pereira, A. L., \& Lapa Esteves, M. (2010). A importância de um abraço! INFAD Revista de Psicologia, 1 (1), 143-148.

Pereira A. S., et al. (2018). Metodologia da pesquisa científica. Ed. UAB/NTE/UFSM. https://repositorio.ufsm.br/bitstream/handle/1/15824/Lic_C omputacao_Metodologia-Pesquisa-Cientifica.pdf?sequence=1.

Rolnik, S. (2006). Cartografia sentimental: transformações contemporâneas do desejo. Rio Grande do Sul: Suliana.

Sampaio, A. T. L. (2009). Universo encantado do cuidado a autopoese docente: uma viagem epistemológica transdisciplinar. 235 f. Tese (Doutorado) - Curso de Programa de Pós Graduação em Educação, Universidade Federal do Rio Grande do Norte, Natal.

Sampaio, A. T. L., Custódio, C. J. C., Custódio, D. K. S. A., \& Cavalcanti, K. B. (2010). Reconhecendo o território de forma Humanescente: um espaço vivo da saúde. Revista Cultural e Científica da Unifacex, 8 (1), 1-9.

Tesser, C. D., \& Sousa, I. M. C. (2012). Atenção primária, atenção psicossocial, práticas integrativas e complementares e suas afinidades eletivas. Saúde e Sociedade, 21 (2), 336-350.

Tesser, C. D., Sousa, I. M. C., \& Nascimento, M. C. (2018). Práticas Integrativas e Complementares na Atenção Primária à Saúde brasileira. Saúde em Debate, $42(1), 174-188$ 